\title{
Enhancing the In-Role Behaviour and Organizational Citizenship Behaviours in the Workplace: A Multidimensional View for the Role of Ethical Climate
}

\author{
Raghda Abulsaoud Ahmed Younis ${ }^{1} \&$ Aida Said Moawad Elsaid ${ }^{1}$ \\ ${ }^{1}$ Business administration department, faculty of commerce, Cairo University, Egypt \\ Correspondence: Raghda Abulsaoud Ahmed Younis, Cairo University, Giza, Egypt. E-mail: \\ raghdauniv@cu.edu.eg
}

Received: August 26, 2019

Accepted: October 6, 2019

Online Published: November 8, 2019

doi:10.5539/ijbm.v14n12p1

URL: https://doi.org/10.5539/ijbm.v14n12p1

\begin{abstract}
Non-ethical behavior is considered as one of the main reasons of distress any organization could be exposed to. The existence of un-ethical climates, within an organization, may result in several negative behaviors towards this organization and its members. Although previous studies asserted the role of ethical climate in both organizational and individual levels, limited studies considered the role of ethical climate from the multidimensional view. This is besides examining its impact on both the in-role and volunteer behaviours. Moreover, the inconsistency of the previous research findings recall the need to address these relations in different industries. Therefore, the purpose of this paper is to investigate the role of ethical climate from a multi-dimensional view, i.e. testing the five dimensions of ethical climate ( Law and code, Rules, Instrumental, Independence and Caring) in predicting both the in-role behavior and organizational citizenship behaviors (organizational citizenship behaviors towards individuals and towards organizations). Based on the cross-sectional study, a survey data from faculty members were collected and analyzed using structure equation modeling. The findings suggested that ethical climate predicts both behaviors. It, also, revealed that the Independence and Rules dimensions are the most influencing climate dimensions in developing the in-role behavior whereas Caring, rules and Instrumental are positively related to the citizenship behaviors. This study is one of the limited studies that considered the role of ethical climate - from a multidimensional view- in predicting both organizational citizenship behaviors and in-role behavior. In addition, it is one of the earliest studies in the Arab region which tackles such a relationship.
\end{abstract}

Keywords: Ethics, Work-climate, Extra-role behaviors, Organizational citizenship behaviors and Volunteer behavior

\section{Introduction}

Many organizations may suffer from un-ethical climate in the workplace. Such climate results in various negative behaviors towards the organization such as: bribery, extravagancy and subversion (Appelbaw et al., 2005; Tsai \& Huang, 2008; Anaza et al, 2015). It may, also, result in negative behaviors towards the organization members such as: verbal and physical attacks, self-preference, discriminations and violence (Appelbaw et.al, 2005; Shafer et al., 2013; Liu et al., 2018).

Accordingly, scholars have emphasized the need to support the ethics in the workplace and to understand the dimensions of Ethical Climate (EC). A well contributed paper by Cullen et al. (2003) defined ethical related climate as a kind of work-climate which is better known as a bundle of prescriptive climates reflecting the firm procedures, policies, and practices with ethical consequences for both parties within and outside the organization. Ethics are related to the intangible aspects/criteria in decision makings and behaviors across the organizations. These aspects are evaluated by the organizational members based on their own interpretations, cognitions and understandings of what is ethical or unethical. Thus, it is important, for managerial levels, to understand what is really associated with members' beliefs towards the ethical climate in their workplace and to know their impacts on different work-related behaviors.

Although previous studies emphasized the importance of ethical climate in multilevel perspectives. i,e, the importance of ethical climate on organizational performance (Okenyi, Donaldson, Collins, Morton \& Obasi, 
2019; Otaye-Ebede, Shaffakat, \& Foster, 2019 ; Wang \& Hsieh, 2013; Shafer, 2013, 2015; Cullen, 2003; Martain \& Cullen, 2006), and the importance of ethical climate on employee work-related behavior, such as: ethical behaviors (Hassanian \& Shayan 2017), positive work attitudes (Valentine, et al. 2013), organizational commitment (Tsai \& Huang, 2008; Cullen, et al., 2003;Kaur, 2017), job satisfaction (Okpara \& Wynn, 2008) and job performance (Mulki \& Lassk,2019), limited studies investigated the multidimensional ethical climate, and its role in enhancing the extra-role behaviors in organization i.e. organizational citizenship behaviors (OCBs) (ex. Shin2012), as well as, the in-role behaviors (IRBs), specifically, in public service organizations.

Testing the influence of the five dimensions of ethical climate, for both OCBs and IRBs in public universities, is important for many reasons. First, organizational citizenship behaviors are volunteered behaviors; therefore, members are likely to engage in such behaviors when they are motivated by intrinsic motivations i.e. dispositional, intangible and psychological factors (Tang \& Ibrahim, 1998; Raub \& Robert, 2010) whereas IRBs are related to accomplishing duties that are formally part of the job description. IRBs are more likely to be influenced by leader behavior, supervisor and external motivations (Raub \& Robert, 2010; Becker and Kernan, 2003). Thus, the different nature of both behaviors calls the need to investigate whether the ethical context in the workplace is vital-common key for both OCBs and IRBs or not.

Second, there is a debate about which ethical climate dimension relates positively/ negatively to OCBs, and whether ethics could have the same impact on both OCBs and IRBs or not (Leung 2008; Huang, et al. 2012). These inquiries recall the need for studying such relations in different fields of study. Third, the general importance of OCBs in public universities; employees working in pubic organizations are influenced by certain motivators that do not exist in other type of organizations such as: valuing the society (Kim,2006; Ritz, Giauque, Varone \& Anderfuhren-Biget., 2014), ethical values toward the community, helping public and self- sacrifice (Giauque,et.al.,2014). All these motivators encourage OCBs in such organizations specifically in the Middle East countries where individuals value the social exchange and relationships and may experience OCBs due to self-stem motivations factors (Tang \& Ibrahim, 1998).

Based on the above reasoning, we expect that the perception of ethical dimensions in such organizations may reveal more citizenship behavior towards the organization itself, not only towards the external community. Based on the pre-mentioned discussion, this paper attempts to investigate how the ethical climate dimensions relate to both citizenship behaviors as well as IRBs in public universities.

\section{The Multidimensional View of Ethical Climate}

The concept of the ethical climate was first conceptualized by Victor \& Cullen (1988) who defined the climate as the employees' awareness of organizational practices, behaviors, the regulations, rules, values and procedures as being of ethical content (Cullen et al., 2003). This climate is linked to the awareness of members that decision-making and regulatory actions have ethical consequences for both parties within and outside the organization (Arnaud, 2010; Jha et al, 2017). Simply, it is the perception of what constitutes right behavior (Martin \& Cullen 2006). Such climates arise when members believe that:

(a) certain sets of ethical reasoning are used as standards or norms for decision-making within the firm (Cullen et al., 2003), Therefore;

(b) Ethical decisions have been made by individuals inside organizations, and ;

(c) Subsequent behaviors in response to ethical dilemma (Martin \& Cullen 2006).

Within the sociology, applied psychology and organizational behavior science, researches increasing interest has surrounded the important of organizational work- climates (Martin \& Cullen 2006). Previous researches have released that ethical climate is a type of organizational work climate. It was considered as a part of the organizational culture which expresses two fundamental aspects: First, the commitment to the ethical values, and Second, the extent to which this commitment affects their behaviors (Appelbawet et al., 2005; Shafer et al, 2013). Moreover, the ethical climate can also be seen as the extent to which employees adhere to their responsibilities towards organizational aspects such as: their commitment to systems, procedures, goals and functions (Kwon Choi et al., 2013). Based on the resource-based theory, the ethical climate can be recognized as one of the intangible resources related to the ethical norms, values and behaviors inside and outside the organization-with external parties (Manroop et al., 2014; Jha et al., 2017). Thus, ethical climate, as intangible resources, can't be purchased; it is embedded, developed within the organizational culture and climate through the time (Choi et al., 2013; Shafer, 2015), and it is considered as a source for competitive advantage (Barney, 2000).

Following the Ethical Climate theory Model that was first addressed by Victor \& Cullen (1988) and other 
successive studies (ex. Martin \& Cullen 2006; Tsai \& Hung 2008). there are two theoretical dimensions for the ethical climate: the ethical standards, and the locus of analysis. Ethical Standards refer to the set of principles and values that are used to judge the various behaviors and state whether they are ethical or not (Martin \& Cullen 2006; Laratta 2010; Kwon Choi et al. 2013). These ethical standards are divided into three sub-constructs: egoism, benevolence, and principal standard.

As for Egoism, it indicates the belief that decisions are made to serve self-interest and organization interest, i.e. individuals act and take decisions in different situations under the criterion of maximizing their personal self-interest and organization interests (Appelbaw et al., 2005; Alicia, 2008; Parboteeah \& Kapp 2008; Kwon Choi et al., 2003). Regarding Benevolence (Tasi \& Hunang 2008), it indicates the belief that the decisions based on the concern of well-being, i.e. the interest is to maximize the benefit to the largest possible sector of individuals (Cullen et al., 2003; Elci \& Alpkan, 2009). While third construct is the Principal Standards, which indicate that the main considerations are the rules, principles and values in the decision-making process (Arnaud, 2010; Kaur, 2017).

On other hand, the locus of analysis (the second theoretical dimension in the theory) is classified to the three former constructs according to their application to organizational context individual, local, and cosmopolitan, and is also divided into three levels of analysis. The individual locus is related to self-interest guide behavior (Cullen, 2003; Martin \& Cullen, 2006; Laratta, 2009). Due to the absence of organizational norms, individuals may take decisions alone based on moral logic which arise from their beliefs and values (Martin \& Cullen, 2006). while the local aspect relates to the organization as a whole. It involves the process of applying ethical standards at the group level (within the organization itself). Finally, the cosmopolitan aspect relates to the community or the society in general; it can involve subjective evaluations regarding organizational effectiveness (Alcatel, 2009; Appelbeaw et al., 2005; Alci \& Alpakan, 2009), or adhering to the social responsibility of the organization (Laratta, 2009; Shaferb, 2015); therefore, the crossing of the two theoretical dimensions forming nine climate types ( 3 patterns for locus of analyses $\mathrm{x} 3$ patterns for ethical standards).

These climate types don't necessarily exist in the same organization, but each organization has its own patterns according to its conditions. There are five common climates that are most noticeable by scholars:

1- Instrumental Climate: it relates to the egoistic criterion where employees believe that all the decisions are made to support self-interest, company's interests, or provide overall benefits (Cullen et al., 2003; Parboteaah \& Kappa, 2008; Shafer, 2015).

2 - Caring Climate: it relates to the benevolence criterion and indicates the concern for other people. members in this climate have honest and faithful interest regarding people who might be influenced by their ethical decisions and behaviors, i.e. parties within and outside the organization (Martin \& Cullen, 2006; Manroop et al., 2014; Zoghabi et al., 2016).

3. The rules climate: it relates to applying the rules and regulations as means for achieving the organization objectives and reducing the work errors (Zoghahi et al., 2016; Kaur 2017; Jha et al., 2017).

4- Law \& Code Climate: employees in this climate committed to the codes and regulations of their professionalism and/ or any other formal authority such as: doctors - teachers - lawyers (Elci \& Alpkan, 2009; Argwall, 2017; Al Danzabal \& Pike, 2017).

5. The independence climate: it relates to the principle ethical criterion. Regarding this climate, employees behave according to their own moral or ethics values and believes, which is based upon a set of principles (Appelbaw et al., 2005; Eelfi \& Alpkan, 2009).

\section{Ethical Climate and Work-Related Behaviors}

There are different types of climates in the workplace; scholars suggested that each type of these climates could serve as a facilitator for a specific work outcome (Adel and Younis, 2019; Younis, 2019). Although ethical climate relates to various work outcomes, this study suggests that ethical climate is more critical for volunteer behaviors i.e. OCBs. Thence, throughout the following discussions we will: first, introduce how EC relates to different work-related behaviors, then, we will review the literature that may support our suggestions.

Ethical climate can be a powerful tool the management can use to reinforce behaviors in the workplace such as innovation (Dimitriou \& Ducette, 2018; Pan, Chen, Hao \& Bi, 2018). Studies emphasized how ethical climate can enhance positive work-outcomes; regarding this, Valentine, et al. (2013) tested the relation between employees' perceptions for organizational ethics and positive work attitudes among 187 professionals in several US funding organizations. The study defined organizational ethics as the extent to which the organization boosts an environment that support ethical practices and policies. Other studies highlighted the impact of ethical climate 
on employees' behaviors such as: ethical behavior. Studies have shown that there is an impact of ethical climate on ethical behavior ( $\mathrm{Lu} \&$ Lin, 2014; Hassanian \& Shayan, 2017;Arnaud, 2010; Kwon Choi et al. 2013; Demitras \& Akdogan, 2015; Alicia, 2008; Wu et al. 2015;Cullen, 2003; Monroop et al. 2014;Lawter et.al. 2014). For example, the study of Hassanian \& Shayan (2017) showed that the ethical climate has a positive impact on the ethical behavior of the nurses. The study presented the concept of ethical behavior in details explaining that one of the characteristics of this behavior is the individual interest in maximizing benefits for both the organization and individuals, which is closely associated with volunteer behavior. In addition, a recent study found out that Caring-Ethical climate can decrease unethical behaviors such as harassment and violation due to the perception of organizational support (Sguera, Bagozzi, Huy, Boss, \& Boss, 2018).

Similarly, other studies have shown the impact of ethical climate dimensions on organizational commitment (Tsai \& Huang, 2008; Cullen, et al., 2003; Kaur, 2017) and job satisfaction (Okpara \& Wynn, 2008). For example, Borhani et al. (2014) showed the relationship between the five dimensions of ethical climate and organizational commitment of nurses. The results revealed some evidences for the role of professionalism, rules, caring, instrumental and independence. In the same context, Dinc and Huric (2017) studied the effect of four dimensions of the ethical climate on both organizational commitment and job satisfaction. The results indicated that all the dimensions related to job satisfaction except for independence whereas there are significant variations in the impact of the ethical climate dimensions on organizational commitment. Another study by Saur and Khuntia (2004) examined the impact of the ethical climate on the behavior of managers in private and public organizations, and the results revealed that ethical climate could predict performance, job involvement, effective commitment, job satisfaction, and taking initiative behaviors.

Concerning the volunteer behaviors, it was found that ethical work climate relates to a lot of favorable outcomes such as helping and volunteer behaviors (Otaye-Ebede, Shaffakat, \& Foster, 2019; Sguera et al., 2018). Scholars have distinguished between two types of performance; the in-role behavior and the organizational citizenship behaviors (Williams \& Anderson, 1991). The former type represents the duties and responsibilities undertaken by the employees and stated within the job descriptions (e.g. work full 8 hours a day; complete assigned duties on time; complying with rules and regulations) while the latter refers to the voluntary behavior that isn't enforceable or formal requirement in the job description. this behavior positively affects organizational overall performance and effectiveness (Organ, 1988).

The dimensionality of OCBs was a debate for years; these dimensions which was first constructed by Williams and Anderson (1991), and widly used by prior researches (Hui, Law, \& Chen, 1999;Werner,1994) is being used in this research. The first dimension is organizational citizenship behavior towards indviduals (OCBIs); it invovles citizenship behaviors toword colleagues or specific members, for instance, helping others when they have heavy work loads. Such behaviors reflect altruism and courtesy (LePine, Erez \& Johnson, 2002). The second dimension is organizational citizenship behavior toward organization (OCBOs), which implies the citizenship behaviors that directly affect organization such as attending above the norm. These behaviors relflect sportsmanship, civic virtue, and conscientiousness (LePine, Erez, \& Johnson, 2002).

Organizational citizenship behaviors are much related to the organizational values (Marinova, et al., 2018). Based on the social exchange theory, individuals engaged in social exchange relationships according to the reciprocity principle. Accordingly, scholars assumed that when employees perceived the ethical standards, actions, procedures, or decisions in the work place, they are likely to engage in OCBs in return (Leung, 2008) due to their perception of organizational support and care (Sguera et al., 2018). Scholars indicated some evidences about ethical climate - organizational citizenship behavior. For example, Shin (2012) tested a model of the antecedents and outcomes of the ethical climate within large sample of 6,000 employees in South Korea. The results revealed that the ethics are affected by the leadership of the company, in addition, the ethical climate influences the organizational citizenship behaviors for employees. Although this study tested the ethical climate and its relation to OCBs, it measured the effect of only two dimensions of such a climate as well. Another study by Shapira-Lishchinsky \& Raftar-Ozery (2016) which examined the factors affecting the organizational citizenship behavior among teachers. The results of the study showed that teachers' perceptions of the existence of an ethical climate overall (without considering the different effects of heir dimensions) is related to organization citizenship behavior towards students and work.

Besides, a well contributed study by Leung (2008) proposed that some of the ethical climates may have negative impact on OCBs across Hong Kong- based companies. The results of the study revealed that the independent climate contributes negatively to some dimensions of OCBs because such a climate maybe concerned with self-interest standard while laws and rules climate have positive effect on the behavior of organizational citizenship because they are more concerned with universal rights and humanity. Moreover, the author didn't 
find a significant relationship between ethical climate dimensions and in-role behavior.

In the same way, Huang, et al. (2012) investigated the impact of different dimensions of the ethical climate across 352 nurses; the study indicated that none of the ethical climate dimensions had an impact on the in-role behavior; however, the rules, laws and code, and instrumental dimensions are related to organizational citizenship behavior toward individuals (OCBIs). Furthermore, rules and caring are related to organizational citizenship behavior toward organization (OCBOs).

To sum up, although previous studies investigated the role of the ethical climate in supporting the work behavior and attitudes, there are limited studies which emphasized the role of each dimension for ethical climate in supporting both in-role behaviors and OCBs behavior, adding to that the inconsistency in the results (i.e. the different effects of ethical dimensions on work behavior) which recalled the need to do more researches about ethical-work behaviors including OCBs. Therefore, we developed the following hypothesis which conceptualized in the research model (Fig.1).

H1: The ethical climate dimensions will be positively associated with the In-role behavior.

$\mathrm{H} 2$ : The ethical climate dimensions will be positively associated with the organizational citizenship behaviors.

H2a: The ethical climate dimensions will be positively associated with the organizational citizenship behaviors toward individuals.

H2b: The ethical climate dimensions will be positively associated with the organizational citizenship behaviors toward organization.

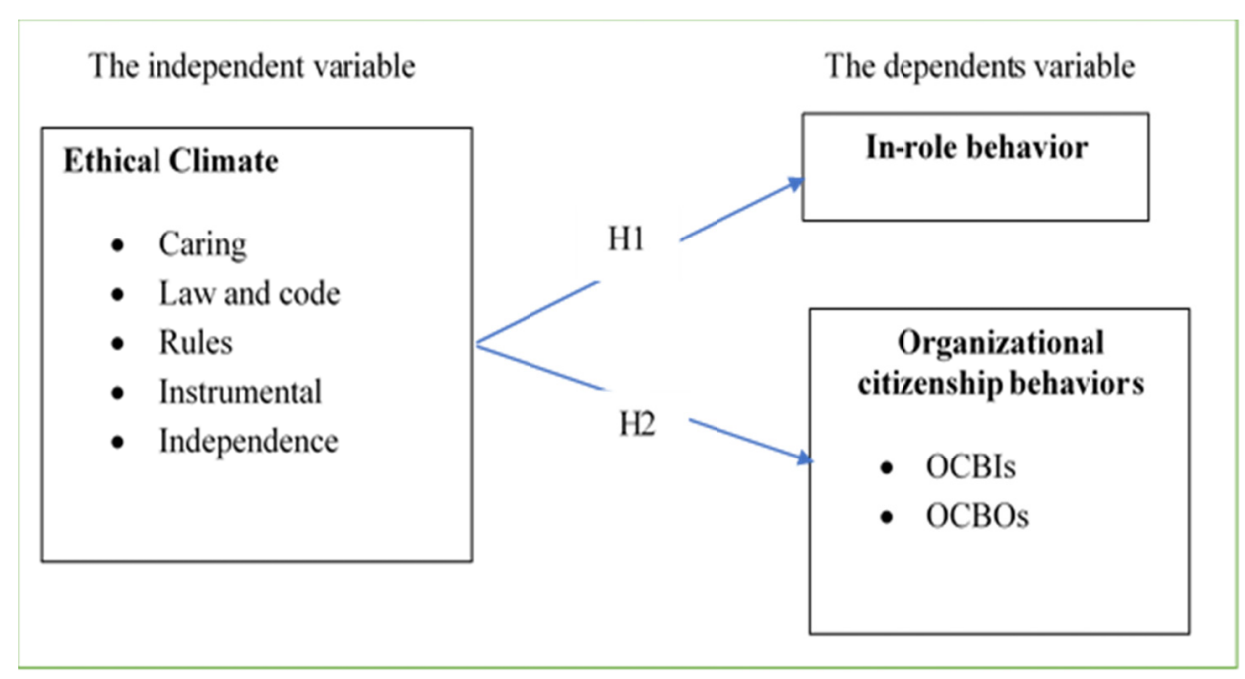

Figure 1. Conceptual research model

\section{Research Method}

The Egyptian higher- education institutions were viewed as an attractive field of study by scholars (ex. Adel and Mahrous, 2018). The research population was based on three main large public universities in Egypt. These universities were chosen because they have the largest number of faculty members, compared to other universities located in Egypt according to the supreme council of universities in Egypt (SCU,2018). A questionnaire was designed and employed to collect data for our field of interest. The questionnaire was distributed among 442 faculty staff members within public universities; the respondent rate reached $88 \%$, with 370 valid questionnaires out of 390 . The sample characteristics are shown in Table 1 . The table shows that more than $40 \%$ of the sample size were aged between $40-50$ years, and the work experience varied between the sample subjects ( $37 \%$ of the subjects were between $10-20$ years of work experience), and the males recorded $50 \%$ of the subjects.

This current study relied on perceptual measures in capturing all the data for the analysis.

Work behaviour- dependent variable: the in- role work behaviour and organizational citizenship behaviour were measured using an instrument developed by Williams \& Anderson, (1991) which measures OCBs along multiple 
dimensions rather than one dimension using a five-point Likert scale with ranged from "strongly agree" to "strongly disagree."

Ethical climate - independent variable: the variable index encompassed 26 items adapting from Victor \& Cullen, (1988), and stemming from five widely reported dimensions: caring, independence, law and code, instrumental and rules. Response options on a five-point Likert-type scale ranged from "strongly disagree" to "strongly agree".

Table 1. The sample characteristics

\begin{tabular}{llc}
\hline Sample & Frequency & Percentage \% \\
\hline Age & & \\
$<30$ years & 34 & 9.2 \\
30 - less than 40 & 74 & 20.0 \\
$40-$ less than 50 & 175 & 47.3 \\
More than 50 years & 87 & 23.5 \\
Work experience & & \\
$<$ 10 years & 76 & 20.5 \\
10 - less than 20 & 137 & 37.0 \\
20 - less than 30 & 116 & 31.4 \\
More than 30 years & 41 & 11.1 \\
Gender & & \\
Male & 185 & 50.0 \\
Female & 185 & 50.0 \\
\hline
\end{tabular}

\section{Data Analysis and Results}

For assessing the validity for the constructs, the Confirmatory Factor Analysis was processed using both SPSS and AMOS (Table 2). The researcher evaluated the construct reliability by conducting Composite Reliability (CR) and Cronbach's Alpha Test. The results were at acceptance scores (Malhorta, 2010); the composite reliability scores for the research constructs are between 0.76 to 0.89 . moreover, we conduct Cronbach's alpha test to assert the constructs 'reliability and the results indicated that the scores were all above 0.7 .

Regarding the Construct validity, we test it by estimating each measure convergent, discriminate validity and factor loading for each item. Construct, convergent, and discriminate validity were demonstrated in several articles (e.g. Asiaei \& Jusoh, 2015; Chahal \& Jyoti, 2016). Regarding the convergent validity, the Average Variance Extracted (AVE) was considered. The AVE scores were all above the acceptance level which is 0.5 . the scores range between 0.51 (for the independent climate) and 0.71 (for the instrumental climate). In addition to the convergent validity test. This paper considers also the discriminate validity test.

Discriminant validity was tested by comparing the square root of AVE for each construct in the research model with the correlations with other constructs in the research model (fornell \& larcker, 1981; Hair, Anderson, Babin, \& Black, 2010). In order to assert discriminant validity, the square root for AVE score for each construct should be more than its correlation with the other constructs in the research model. the results in table2. indicated that AVE scores for the research variables were more than their correlations with the rest of the variables which, clearly, supported the discriminate validity for the constructs. For example. The square root of AVE for the in-role behaviour (0.74) is greater than the correlations scores with other variables (caring, rules, law, instrumental, independent, OCBI and OCBO). 
Table 2. Results of confirmatory factor analysis

\begin{tabular}{|c|c|c|c|c|c|c|c|c|c|c|}
\hline & CR & AVE & IRB & Caring & Law & Rules & Independent & Instrumental & OCBIs & OCBOs \\
\hline IRB & 0.89 & 0.55 & 0.74 & & & & & & & \\
\hline Caring & 0.89 & 0.54 & 0.10 & 0.74 & & & & & & \\
\hline Law & 0.86 & 0.62 & -0.01 & 0.11 & 0.79 & & & & & \\
\hline Rules & 0.80 & 0.52 & 0.21 & 0.11 & 0.10 & 0.72 & & & & \\
\hline Independent & 0.76 & 0.51 & 0.26 & 0.17 & 0.08 & 0.34 & 0.72 & & & \\
\hline Instrumental & 0.94 & 0.71 & 0.07 & -0.07 & -0.05 & -0.02 & 0.14 & 0.84 & & \\
\hline OCBI s & 0.89 & 0.57 & 0.48 & 0.17 & 0.09 & 0.18 & 0.08 & 0.18 & 0.75 & \\
\hline OCBOs & 0.89 & 0.55 & 0.38 & 0.18 & 0.11 & 0.24 & 0.13 & 0.01 & 0.39 & 0.74 \\
\hline
\end{tabular}

Note: the bold numbers are the square root of $A V E$.

To answer the research questions, the structure equation modeling was used to empirically test the proposed model. There were two main steps which were used in this paper; an initial step included measuring the SEM model fit (Table 3). And the second step is to test the hypotheses. Depending on the Amos output, the most common indices were illustrated in the following table. According to the indices presented in the table below, all extracted fit values are within the acceptable levels supporting the possibility to conduct the regression analysis (second step).

Table 3. Overall model goodness of fit for the structure model

\begin{tabular}{lc}
\hline \multicolumn{1}{c}{ Model fit index } & Scores \\
\hline Minimum sample discrep ancy divided by degrees of freedom (CMIN/DF) & 1.80 \\
Goodness-of-fit index (GFI) & 0.83 \\
Comparative fit index (CFI) & 0.92 \\
Root mean square error of approximation (RMSEA) & 0.04 \\
Normed fit index (NFI) & 0.85 \\
Tucker-Lewis coefficient (TLI) & 0.92
\end{tabular}

The second step included testing the hypotheses. The Multiple Regression Analysis was processed via Amos (V.21) to test our hypotheses. According to the first hypothesis, which proposed that EC has positive impact on in-role behavior in the higher-education institutions, the results in Table 4 showed that only Independence and Rules are both impacting in-role behavior at significant level 0.05 while there wasn't any impact for other dimensions on IRBs at this significant level. This means that H1 was partially supported. Considering the effects of EC multiple dimensions on the organizational citizenship behaviors in the higher-education institutions, the results revealed that Caring, Instrumental and Rules are related to OCBs with $R^{2}$ 0.18. Additionally, the researcher retested the model (via Amos program) by considering OCBIs and OCBOs asi dependent variables in order to estimate the significant effect of EC on both of them separately. The findlings revealed that the regressions were significant for Caring, Instrumental and Rules on OCBIs with $R^{2} 0.09$; however, there were significant impacts for Caring and Rules only on OCBOs. This means that H2 was partially supported. 
Table 4. The regression analysis

\begin{tabular}{lllll}
\hline ETHICAL CLIMATE DIMENSIONS & OCBI & OCBO & OCBs & IRBs \\
CARING & $0.17^{* *}$ & $0.16^{*}$ & $0.25^{* *}$ & 0.06 \\
INDEPENDENCE & 0.05 & 0.10 & 0.10 & $0.20^{*}$ \\
INSTRUMENTAL & $0.19^{*}$ & 0.02 & $0.18^{* *}$ & 0.04 \\
LAW AND CODE & 0.07 & 0.06 & 0.10 & -0.04 \\
RULES & $0.10^{*}$ & $0.12^{*}$ & $0.18^{* *}$ & $0.22^{*}$ \\
$\boldsymbol{R}^{2}$ & 0.09 & 0.09 & 0.18 & 0.07 \\
\hline
\end{tabular}

Notes. ${ }^{*} \mathrm{p}<0.05 ; * * \mathrm{p}<0.01$

Additional to the above statistical analyses. The researchers conducted one-way ANOVA analysis for the demographic variables (age, gender and work experience) to see whether there are significant variations in citizenship behaviors and in-role behavior among individuals or not. According to the findings in table 5, the OCBIs, OCBOs and in-role behavior differ across individuals' age; older staff members (more than 50 years) have higher citizenship behaviors and in-role behavior than younger staff members. moreover, the results of ANOVA revealed that OCBIs and in-role behavior differ according to the work experience of every member, that is to say, staff members who have experience more than 30 years were supposed to have higher citizenship behavior towards individuals and able to fulfill their formal work duties more than others. Finally, the results showed no significant variation for the dependent variables (OCBIs, OCBOs and IRBs) across staff members regarding the gender.

Table 5. one -way ANOVA test and T -test for sample characteristics

\begin{tabular}{lcccccc}
\hline & \multicolumn{2}{c}{ OCBIs } & \multicolumn{2}{c}{ OCBOs } & \multicolumn{2}{c}{ IRBs } \\
& Mean & F & Mean & F & Mean & F \\
\hline Age & & & & & & \\
$<30$ years & 3.64 & $4.15^{* *}$ & 4.26 & $2.71^{*}$ & 4.12 & $3.08^{*}$ \\
$30-$ less than 40 & 3.90 & & 3.96 & & 3.96 & \\
40 - less than 50 & 4.02 & & 4.15 & & 4.16 & \\
More than 50 years & 4.15 & & 4.29 & & 4.32 & \\
Work experience & & & & & & \\
$<10$ years & 3.74 & $4.12^{* *}$ & 4.04 & 1.47 & 3.98 & $4.09 * *$ \\
10 - less than 20 & 4.00 & & 4.12 & & 4.10 & \\
20 - less than 30 & 4.10 & & 4.26 & & 4.24 & \\
More than 30 years & 4.13 & & 4.21 & & 4.43 & \\
Gender & & & & & & \\
Male & 4.02 & .022 & 4.19 & 1.52 & 4.19 & .86 \\
Female & 3.97 & & 4.13 & & 4.12 & \\
\hline
\end{tabular}

Notes. $* * \mathrm{p}<0.01, * \mathrm{p}<0.05$.

\section{Discussions, Limitations and Future Suggestions}

The ethical climate involves the perception of ethical values in organizational practices, behaviors, rules, and procedures by employees (Cullen et al., 2003). This paper investigates and tests an integrated model that includes multi-dimensions of the ethical climate with the work behaviors, in-role behavior and organizational citizenship behaviors. The results indicated various findings regarding the influence of each dimension on the ethical climate. Regarding the in-role behavior, it has been clear that the ethical climate, in general, impacts such behavior. The main significant effect was for independence and rules dimensions. These findings contradict previous studies which found no significance for ethical climate on IRBs (Huang, et al., 2012; Leung, 2008). These results show that members who follow their own principles, concepts, and values (resulting from their own experiences and knowledge) and applying them at work, routine procedures and decision-making processes will be able to accomplish their tasks effectively as a result of the independence and the speed of self-evident in dealing with different situations. This shows that when members follow the organizational rules in every situation or problem they face, they would be able to reduce the task-errors probability and achieve better work outcomes (i.e. In-role behavior). To sum up, there is a need to adhere individual's own principles as well as 
organizational rules to assure work accomplishment effectively.

Concerning the organizational citizenship behaviors, the ethical climate dimensions relatively varied in its effect compared to the in-role behavior. The regression analysis has shown that the ethical climate plays a significant role in achieving such behaviors in the workplace as the $R^{2}$ findings revealed that EC predicts OCBs more than IRBs in the field of study. Moreover, the research findings showed that OCBIs and OCBOs differ in their reactions toward the ethical climate dimensions. Caring, Rules and Instrumental are the three dimensions that positively impacted OCBIs across staff members while Caring and Rules are the two dimension which positively influenced OCBOs across staff members. These results agree with previous researches (Leung, 2008; Huang, et al. 2012), specifically, those which were done within the Middle East countries and asserted that individuals in such countries value social exchange and collaborations (Tang \& Ibrahim, 1998).

Furthermore, our findings asserted that the members' sense of Caring towards individuals, groups (colleagues in the work), and even external parties (customers and community) may enhance the will to carry out voluntary actions which directly impact the organization or indirectly-via helping specific individuals within the organization. The members' perceptions regarding respecting organizational rules and procedures by others may result in OCBIs and OCBOs. In other words, when individuals follow the rules and don't make decisions according to their personal interests and desires, other members may be motivated to work and develop in their workplace by acting citizenship behaviors towards organization and towards individuals. Otherwise, the perceptions of unrespecting or unfollowing organizational rules may result in negative impressions and attitudes towards the workplace, for instance, being exposed to unfairness or inequality perceptions which may result in negative behavior towards organization and may ruin the organization image. Thus, the results agree with previous research regarding instrumental - OCBIs relationship (Huang, et al. 2012), i.e. members perceive the way individuals act to protect self-interests as well as organization interests as positive climate and relates to citizenship behavior towards individuals.

Finally, although testing the dependent variables variation across the sample characteristics wasn't one of our research objectives or paper hypotheses, our results reveal important implications for age and experience in the proposed model. It has witnessed that individuals with the age range of 50 years and above experience high levels of OCBs and IRBs than the age range below 50. Furthermore, individuals who have work experience more than 30 years in academic career are experiencing high levels of OCBIs and IRBS whereas individuals who have work experience between 20 and 30 years have more OCBOs than others.

This paper has many theoretical implications. First, limited studies have investigated the impact of ethical climate on both in-role and organizational citizenship behaviors in higher-education institutions. It was vital to test whether ethical context in the workplace has the same impact on both behaviors or not, specifically, in public organizations where individuals are guided by different antecedents and motivators. Second, our study tests the ethical climate from a multi-dimensional view where it is important to make comparisons and evaluations for which climate could positively impact employees' behaviors in such organizations.

There are several empirical implications for this research. first, this research presenting and sustaining the ethical climate for public service institutions, which would support the fourth and eighth pillars of Egypt's strategy of sustainable development (Egypt Vision 2030, 2016) - transparency, efficiency, and culture pillars. This support can take several ways: (a) EC guides service institutions in how to serve public society more effectively by engaging in OCBs' behaviors. (b) Ensuring ethical values, norms and climate in workplace could be a mean to minimize and overcome unethical practices such as discriminations, bias, un-justice, harassment and inequality as suggested by previous studies (Gronloud et al, 2019; Sguera et al, 2018).

Second implication is guiding managers from different disciplines and levels where managers and leaders shouldn't only be keen to follow the rules stated by the organization, but also to ensure that all workers are aware of their commitment and respect to these rules. Moreover, managers have to make sure that there won't be existence for personal aversion, nepotism or discrimination perceptions. Third, it is important to clarify the consequences of ethical climate for staff members such as the existence of ethics in the organizational multi-levels, i.e. interpersonal, local and cosmopolitan level, which could impact the overall company image, and in turn, could impact members' career objectives and vice versa. Fourth, managers may use formal and informal meetings as channels for exchanging and sharing information about caring scenarios or helping actions (actions that were already done or will be considered in the future with different parties via organization) such as social responsibility actions.

The Fifth implication for this paper relates to human resource management. previous researches have widely addressed the implication of human resources management practices in the individual and organizational level 
(ex. Younis,2018). therefore, HR practices can be used to establish ethical principles among organizational members through: (a) Including the ethical features of ethical climate in the job description and ensuring the existence of these features when hiring new candidates. (b) Training must include ethics of professionalism and their role in improving the image of the company. (c) Promotions and performance appraisal may involve Caring, Instrumental and Rules criteria for evaluation. (d) Finally, managers may encourage older members who have more academic experience and OCBOs behaviors to be an honorable example of ethics to other members.

As any other research, this research has some limitations. First, we considered the members' point of view when assessing the ethical climate and work behavior. This is due to the nature of the field of study. It was difficult to find a single supervisor for each member (compared to the business organizations) as the member's behavior may be evaluated by the supervised professors, the head of the department, or the faculty Dean. Second, the researcher suggests testing the model in different industries and with different levels other than testing the ethical climate model in universities. The researcher suggests to find and investigate which intervening variables can mediate the relation between the ethical climate and the overall organizational performance as well.

\section{References}

Adel, H. M., \& Mahrous, A. (2018). Sustainability communication and evaluation: A practice-based case study on British-Egyptian universities value-chain. Proceedings of the 32nd Annual International Conference of The British Academy of Management 2018: Driving Productivity in Uncertain and Challenging Times, Bristol Business School, University of the West of England.

Adel, H. M., \& Younis, R. A. A. (2019). Using co-creating mass-customisation and innovation climate for enhanced value. Journal of Humanities and Applied Social Sciences, 1(1), 25-42. https://doi.org/10.1108/JHASS-05-2019-002

Appelbaum, S. H., Deguire, K. J., \& Lay, M. (2005). The relationship of ethical climate to deviant workplace behaviour. Corporate Governance: The international journal of business in society, 5(4), 43-55. https://doi.org/10.1108/14720700510616587

Arnaud, A. (2010). Conceptualizing and measuring ethical work climate: Development and validation of the ethical climate index. Business \& Society, 49(2), 345-358. https://doi.org/10.1177/0007650310362865

Barney, J. (1991). Firm resources and sustained competitive advantage. Journal of management, 17(1), 99-120. https://doi.org/10.1016/S0742-3322(00)17018-4

Becker, T. E., \& Kernan, M. C. (2003). Matching commitment to supervisors and organizations to in-role and $\begin{array}{lllll}\text { extra-role } \quad \text { performance. } & \text { 3uman performance, }\end{array}$ https://doi.org/10.1207/S15327043HUP1604_1

Borhani, F., Jalali, T., Abbaszadeh, A., \& Haghdoost, A. (2014). Nurses' perception of ethical climate and organizational commitment. Nursing ethics, 21(3), 278-288. https://doi.org/10.1177/0969733013493215

Cullen, J. B., Parboteeah, K. P., \& Victor, B. (2003). The effects of ethical climates on organizational commitment: A two-study analysis. Journal of Business Ethics, 46(2), 127-141. https://doi.org/10.1023/A:102508981945

Dimitriou, C. K., \& Ducette, J. P. (2018). An analysis of the key determinants of hotel employees' ethical behavior. Journal of Hospitality and Tourism Management, 34, 66-74. https://doi.org/10.1016/j.jhtm.2017.12.002

Dinc, M. S., \& Huric, A. (2017). The impact of ethical climate types on nurses' behaviors in Bosnia and Herzegovina. Nursing ethics, 24(8), 922-935. https://doi.org/10.1177/0969733016638143

Egypt vision 2030 (2016). Sustainable development strategy - Egypt's vision 2030. available at: http://sdsegypt2030.com

Elçi, M., \& Alpkan, L. (2009). The impact of perceived organizational ethical climate on work satisfaction. Journal of Business Ethics, 84(3), 297-311.

Hassanian, Z. M., \& Shayan, A. (2019). The mediating effect of ethical climate on religious orientation and ethical behavior.Nursing ethics, 26(4), 1114-1127. https://doi.org/10.1177/0969733017738133

Huang, C. C., You, C. S., \& Tsai, M. T. (2012). A multidimensional analysis of ethical climate, job satisfaction, organizational commitment, and organizational citizenship behaviors. Nursing Ethics, 19(4), 513-529.

Hui, C., Law, K. S., \& Chen, Z. X. (1999). A structural equation model of the effects of negative affectivity, leader-member exchange, and perceived job mobility on in-role and extra-role performance: A Chinese case. 
Organizational behavior and human decision processes, 77(1), 3-21. https://doi.org/10.1006/obhd.1998.2812

Jha, J. K., Varkkey, B., Agrawal, P., \& Singh, N. (2017). Contribution of HR systems in development of ethical climate at workplace: A case study. South Asian Journal of Human Resources Management, 4(1), 106-129. https://doi.org/10.1177/2322093717705183

Kaur, J. (2017). Exploring relationships among ethical climate types and organizational commitment: A case of Indian banking sector. Journal of Indian Business Research, 9(1), 20-40.

Kim, S. (2006). Public service motivation and organizational citizenship behavior in Korea. International journal of manpower, 27(8), 722-740.

Kipka, C., Morland, M. P., Lawter, L., Rua, T., \& Guo, C. (2014). The interaction between learning styles, ethics education, and ethical climate. Journal of Management Development.

Koo Moon, H., \& Kwon Choi, B. (2014). How an organization's ethical climate contributes to customer satisfaction and financial performance: Perceived organizational innovation perspective. European Journal of Innovation Management, 17(1), 85-106.

Kwon Choi, B., Koo Moon, H., \& Ko, W. (2013). An organization's ethical climate, innovation, and performance: Effects of support for innovation and performance evaluation. Management Decision, 51(6), 1250-1275.

Laratta, R. (2009). Ethical climate in nonprofit organizations: A comparative study. International Journal of Sociology and Social Policy, 29(7/8), 358-371.

Laratta, R. (2010). Ethical climate in nonprofit and government sectors: the case of Japan. Social Enterprise Journal, 6(3), 225-249.

LePine, J. A., Erez, A., \& Johnson, D. E. (2002). The nature and dimensionality of organizational citizenship behavior: a critical review and meta-analysis. Journal of applied psychology, 87(1), 52.

Leung, A. S. (2008). Matching ethical work climate to in-role and extra-role behaviors in a collectivist work setting. Journal of Business Ethics, 79(1-2), 43-55.

Liu, Y., Zhao, S., Li, R., Zhou, L., \& Tian, F. (2018). The relationship between organizational identification and internal whistle-blowing: the joint moderating effects of perceived ethical climate and proactive personality. Review of Managerial Science, 12(1), 113-134.

Lu, C. S., \& Lin, C. C. (2014). The effects of ethical leadership and ethical climate on employee ethical behavior in the international port context. Journal of Business Ethics, 124(2), 209-223.

Manroop, L. (2015). Human resource systems and competitive advantage: an ethical climate perspective. Business Ethics: A European Review, 24(2), 186-204. https://doi.org/:10.1111/beer.12069

Manroop, L., Singh, P., \& Ezzedeen, S. (2014). Human resource systems and ethical climates: A resource-based perspective. Human resource management, 53(5), 795-816. https://doi.org/10.1002/hrm.21593

Marinova, S. V., Cao, X., \& Park, H. (2019). Constructive organizational values climate and organizational citizenship behaviors: A configurational view. Journal of Management, 45(5), 2045-2071. https://doi.org/10.1177/0149206318755301

Martin, K. D., \& Cullen, J. B. (2006). Continuities and extensions of ethical climate theory: A meta-analytic review. Journal of business ethics, 69(2), 175-194.

Mulki, J., \& Lassk, F. G. (2019). Joint impact of ethical climate and external work locus of control on job meaningfulness. Journal of Business Research, 99, 46-56.

Okenyi, E., Donaldson, T. M., Collins, A., Morton, B., \& Obasi, A. (2019). Assessing ethical climates in critical care and their impact on patient outcomes. Breathe, 15(1), 84-87.

Okpara, J. O., \& Wynn, P. (2008). The impact of ethical climate on job satisfaction, and commitment in Nigeria: Implications for management development. Journal of Management Development, 27(9), 935-950.

Organ, D. (1988). Organizational citizenship behavior. MA: Lexington: Lexington.

Otaye-Ebede, L., Shaffakat, S., \& Foster, S. (2019). A Multilevel Model Examining the Relationships Between Workplace Spirituality, Ethical Climate and Outcomes: A Social Cognitive Theory Perspective. Journal of Business Ethics, 1-16. 
Pan, X., Chen, M., Hao, Z., \& Bi, W. (2018). The effects of organizational justice on positive organizational behavior: Evidence from a large-sample survey and a situational experiment. Frontiers in psychology, 8, 2315.

Parboteeah, K. P., \& Kapp, E. A. (2008). Ethical climates and workplace safety behaviors: An empirical investigation. Journal of Business Ethics, 80(3), 515-529.

Podsakoff, P. M., MacKenzie, S. B., Paine, J. B., \& Bachrach, D. G. (2000). Organizational citizenship behaviors: A critical review of the theoretical and empirical literature and suggestions for future research. Journal of management, 26(3), 513-563.

Raub, S., \& Robert, C. (2010). Differential effects of empowering leadership on in-role and extra-role employee behaviors: Exploring the role of psychological empowerment and power values. Human relations, 63(11), 1743-1770. https://doi.org/10.1177/0018726710365092

Ritz, A., Giauque, D., Varone, F., \& Anderfuhren-Biget, S. (2014). From leadership to citizenship behavior in public organizations: When values matter. Review of Public Personnel Administration, 34(2), 128-152. https://doi.org/10.1177/0734371X14521456

Rollins, M., Anaza, N. A., Rutherford, B., \& Nickell, D. (2015). Ethical climate and job satisfaction among organizational buyers: an empirical study. Journal of Business \& Industrial Marketing. https://doi.org/10.1108/JBIM-03-2014-0047

SCU. (2018). Academic staff totals in Egyptian universities report, supreme council of universities in Egypt report.

Sguera, F., Bagozzi, R. P., Huy, Q. N., Boss, R. W., \& Boss, D. S. (2018). The More You Care, the Worthier I Feel, the Better I Behave: How and When Supervisor Support Influences (Un) Ethical Employee Behavior. Journal of Business Ethics, 153(3), 615-628.

Shafer, W. E. (2015). Ethical climate, social responsibility, and earnings management. Journal of Business Ethics, 126(1), 43-60.

Shafer, W. E., Poon, M. C., \& Tjosvold, D. (2013). An investigation of ethical climate in a Singaporean accounting firm. Accounting, Auditing \& Accountability Journal, 26(2), 312-343.

Shapira-Lishchinsky, O., \& Raftar-Ozery, T. (2018). Leadership, absenteeism acceptance, and ethical climate as predictors of teachers' absence and citizenship behaviors. Educational Management Administration \& Leadership, 46(3), 491-510. https://doi.org/10.1177/1741143216665841

Shin, Y. (2012). CEO ethical leadership, ethical climate, climate strength, and collective organizational citizenship behavior. Journal of Business Ethics, 108(3), 299-312.

Suar, D., \& Khuntia, R. (2004). Does ethical climate influence unethical practices and work behaviour?. Journal of Human Values, 10(1), 11-21.

Tang, T. L. P., \& Ibrahim, A. H. S. (1998). Antecedents of organizational citizenship behavior revisited: Public personnel in the United States and in the Middle East. Public Personnel Management, 27(4), 529-550.

Tsai, M. T., \& Huang, C. C. (2008). The relationship among ethical climate types, facets of job satisfaction, and the three components of organizational commitment: A study of nurses in Taiwan. Journal of Business Ethics, 80(3), 565-581.

Victor, B., \& Cullen, J. B. (1988). The organizational bases of ethical work climates. Administrative Science Quarterly, 101-125. https://doi.org/10.2307/2392857

Wang, Y. D., \& Hsieh, H. H. (2013). Organizational ethical climate, perceived organizational support, and employee silence: A cross-level investigation. Human Relations, 66(6), 783-802. https://doi.org/10.1177/0018726712460706

Werner, J. M. (1994). Dimensions that make a difference: Examining the impact of in-role and extrarole behaviors on supervisory ratings. Journal of Applied Psychology, 79(1), 98.

Wu, W., Yu, B., Spender, J. C., Hung, Y. C., Tsai, T. Y., \& Wu, Y. F. (2015). The effects of ethical work climate on organizational commitment in Taiwanese military units. Chinese Management Studies.

Younis, R. (2018). Human Resource Management Practices and the perceived Hospital performance: The mediating role of Intellectual Capital. Scientific Journal for Economic\& Commerce, 48(3), 559-586. https://doi.org/10.21608/jsec.2018.39411 
Younis, R. (2019). Cognitive Diversity and Creativity: The Moderating Effect of Collaborative Climate. International Journal of Business and Management, 14(1). https://doi.org/10.5539/ijbm.v14n1p159

Zoghbi-Manrique-de-Lara, P., \& Guerra-Baez, R. (2016). Exploring the influence of ethical climate on employee compassion in the hospitality industry. Journal of Business Ethics, 133(3), 605-617.

\section{Copyrights}

Copyright for this article is retained by the author(s), with first publication rights granted to the journal.

This is an open-access article distributed under the terms and conditions of the Creative Commons Attribution license (http://creativecommons.org/licenses/by/4.0/). 